\title{
Theoretical Prediction and Synthesis of a Family of Atomic Laminate Metal Borides with In-Plane Chemical Ordering
}

\author{
Martin Dahlqvist,* Quanzheng Tao, Jie Zhou, Justinas Palisaitis, Per O. Å. Persson, and Johanna Rosen*
}

Cite This: J. Am. Chem. Soc. 2020, 142, 18583-18591

Read Online

ABSTRACT: All atomically laminated $M A B$ phases $(M=$ transition metal, $\mathrm{A}=\mathrm{A}$-group element, and $\mathrm{B}=$ boron) exhibit orthorhombic or tetragonal symmetry, with the only exception being hexagonal $\mathrm{Ti}_{2} \mathrm{InB}_{2}$. Inspired by the recent discovery of chemically ordered hexagonal carbides, i-MAX phases, we perform an extensive firstprinciples study to explore chemical ordering upon metal alloying of $\mathrm{M}_{2} \mathrm{AlB}_{2}$ ( $\mathrm{M}$ from groups 3 to 9) in orthorhombic and hexagonal symmetry. Fifteen stable novel phases with in-plane chemical ordering are identified, coined i-MAB, along with 16 disordered stable alloys. The predictions are verified through the powder synthesis of $\mathrm{Mo}_{4 / 3} \mathrm{Y}_{2 / 3} \mathrm{AlB}_{2}$ and $\mathrm{Mo}_{4 / 3} \mathrm{Sc}_{2 / 3} \mathrm{AlB}_{2}$ of space group $R \overline{3} m$ (no. 166), displaying the characteristic in-plane chemical order of

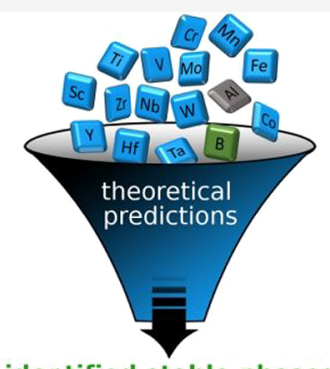

identified stable phases chemical order: 15 chemical disorder: 16

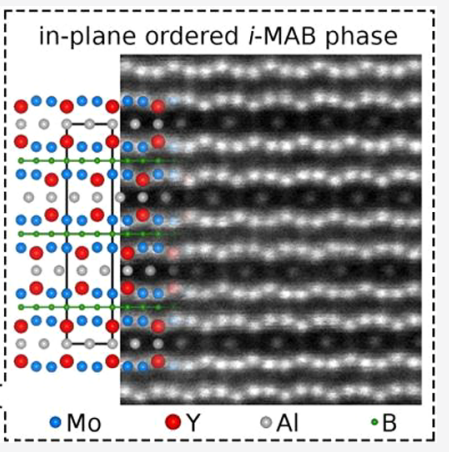
$\mathrm{Mo}$ and $\mathrm{Y} / \mathrm{Sc}$ and Kagomé ordering of the $\mathrm{Al}$ atoms, as evident from $\mathrm{X}$-ray diffraction and electron microscopy. The discovery of $\mathrm{i}-\mathrm{MAB}$ phases expands the elemental space of these borides with $\mathrm{M}=\mathrm{Sc}$, $\mathrm{Y}, \mathrm{Zr}$, Hf, and $\mathrm{Nb}$, realizing an increased property tuning potential of these phases as well as their suggested potential twodimensional derivatives.

\section{INTRODUCTION}

Transition-metal borides and carbides have high melting points and are among the hardest compounds known, which are properties required for both bulk and coating applications. When combined with a third element, they can retain or form atomically layered structures. One such example is $\mathrm{M}_{n+1} \mathrm{AX}_{n}$ (MAX) phases (where $\mathrm{M}$ is a transition metal, $\mathrm{A}$ is an A-group element, and $\mathrm{X}$ is $\mathrm{C}$ and/or $\mathrm{N}$ ) of a hexagonal structure with $\mathrm{Pb}_{3} / \mathrm{mmc}$ symmetry, combining ceramic and metallic attributes. ${ }^{1,2}$ The selective removal of the A element, typically $\mathrm{Al}$, upon etching results in the corresponding two-dimensional (2D) material, a so-called MXene, ${ }^{3}$ which has shown an outstanding potential for a wide range of applications, from energy storage ${ }^{4}$ to electromagnetic interference shielding. ${ }^{5}$

One route to enhancing the materials' elemental space and the associated range of attainable properties is through alloying. This is exemplified by the recent discovery of inplane chemically ordered MAX phase alloys, coined $i$-MAX, which through hexagonal symmetry allow for elemental ordering and the incorporation of metals not found in traditional ternary MAX phases. $^{6-8}$ A key feature of $i$-MAX phases is that by employing different etching protocols the resulting 2D MXene can have in-plane chemical or vacancy ordering, ${ }^{9}$ which is valuable for catalysis and energy storage. ${ }^{6,8}$ Similar in-plane chemical order in 3D-layered transition-metal borides (MAB phases) has, to this date, not been found.

$\mathrm{MAB}$ phases have a large palette of structural variations. From $\mathrm{M}_{n+1} \mathrm{AlB}_{2 n}$ with a single layer of $\mathrm{Al}, n=1-3$ and $\mathrm{M}$ is a transition metal ( $n=1$ in space group Cmmm: $\mathrm{Cr}_{2} \mathrm{AlB}_{2}$, $\mathrm{Mn}_{2} \mathrm{AlB}_{2}$, and $\mathrm{Fe}_{2} \mathrm{AlB}_{2} ; n=2$ in space group Pmmm: $\mathrm{Cr}_{3} \mathrm{AlB}_{4}$; $n=3$ in space group $\left.\mathrm{Cmmm}: \mathrm{Cr}_{4} \mathrm{AlB}_{6}\right),{ }^{10-12}$ to MAlB with double layers of $\mathrm{Al}$ (MoAlB and $\mathrm{WAlB}$ in space group $\mathrm{Cmcm})^{12}$ and $\mathrm{M}_{4} \mathrm{AlB}_{4}$ with double layers of $\mathrm{M}\left(\mathrm{Cr}_{4} \mathrm{AlB}_{4}\right.$ in space group $\mathrm{Immm}) .{ }^{13}$ Note that all structures have orthorhombic symmetry. In particular, $\mathrm{Fe}_{2} \mathrm{AlB}_{2}$ has gained attention as a prospective for a rare-earth free magnetocaloric material with a near-room temperature magnetic phase transition at around $304 \mathrm{~K}^{14,15}$

The chemical diversity of MAB phases has so far been limited to $\mathrm{M}$ from group 6 to 8 and A commonly being Al. Chemical disorder has previously been investigated for synthesized $\left(\mathrm{M}^{\prime}{ }_{1-x} \mathrm{Mo}_{x}\right) \mathrm{AlB}(\mathrm{Cmcm}),{ }^{16}$ with $\mathrm{M}^{\prime}=\mathrm{W}$ and $\mathrm{Cr}$ and $\mathrm{Fe}_{2-x} \mathrm{Mn}_{x} \mathrm{AlB}_{2}{ }^{15}$ ( $\left.\mathrm{Cmmm}\right)$, and theoretically studied for $\mathrm{Fe}_{2-\mathrm{x}} \mathrm{M}^{\prime \prime}{ }_{x} \mathrm{AlB}_{2}(\mathrm{Cmmm})$, with $\mathrm{M}^{\prime \prime}=\mathrm{Cr}$, Mn, Ni, Co. ${ }^{17}$ Chemical order has only been investigated theoretically for the $\mathrm{M}_{3} \mathrm{AlB}_{4}$ structure $(\mathrm{Pmmm})$ with out-of-plane order of $\mathrm{M}^{\prime}$ and $\mathrm{M}^{\prime \prime}$ in $\mathrm{M}_{2}^{\prime} \mathrm{M}^{\prime \prime} \mathrm{AlB}_{4}$ with $\mathrm{M}^{\prime}=\mathrm{Mn}, \mathrm{Fe}$, and $\mathrm{Co}$ and $\mathrm{M}^{\prime \prime}=\mathrm{Cr}$,

Received: July 28, 2020

Published: October 13, 2020 
Mo, and W. ${ }^{18}$ In all cases, the alloying metals encompass the elements found in traditional ternary MAB phases.

All MAB structures display orthorhombic symmetry. The only exception is a recently discovered layered $\mathrm{MAB}$ phase, $\mathrm{Ti}_{2} \mathrm{InB}_{2}{ }^{11}$ with hexagonal $P \overline{6} \mathrm{~m} 2$ symmetry (also a hexagonal subgroup of $P 6_{3} / \mathrm{mmc}$ ). Inspired by this finding and motivated by the previous discovery of $i$-MAX phases, we here use cluster expansion to theoretically investigate the possibility of chemical ordering in MAB-phase alloys. We also perform systematic phase stability calculations for alloying between $\mathrm{M}^{\prime}$ and $\mathrm{M}^{\prime \prime}$ in $\mathrm{M}_{2-x}^{\prime} \mathrm{M}^{\prime \prime}{ }_{x} \mathrm{AlB}_{2}$, where $\mathrm{M}^{\prime}$ and $\mathrm{M}^{\prime \prime}$ are $\mathrm{Sc}, \mathrm{Y}, \mathrm{Ti}, \mathrm{Zr}$, $\mathrm{Hf}, \mathrm{V}, \mathrm{Nb}, \mathrm{Ta}, \mathrm{Cr}, \mathrm{Mo}, \mathrm{W}, \mathrm{Mn}, \mathrm{Fe}$, and Co in the two known $\mathrm{M}_{2} \mathrm{AlB}_{2}$ polymorphs, orthorhombic $\mathrm{Cmmm}$ and hexagonal $\overline{P 6} \mathrm{~m} 2$. The preference for chemical order and disorder is evaluated for all elemental combinations of $\mathrm{M}^{\prime}$ and $\mathrm{M}^{\prime \prime}$.

We identify 15 novel MAB phases with in-plane chemical order, hereafter referred to as $i-\mathrm{MAB}$ phases, that are concluded to be thermodynamically stable up to a temperature of at least $2000 \mathrm{~K}$. To verify these theoretical predictions, we synthesize $\mathrm{Mo}_{4 / 3} \mathrm{Y}_{2 / 3} \mathrm{AlB}_{2}$ and $\mathrm{Mo}_{4 / 3} \mathrm{Sc}_{2 / 3} \mathrm{AlB}_{2}$, and material characterization confirms a structure with space group $R \overline{3} m$ (no. 166) displaying the characteristic in-plane chemical ordering of Mo and $\mathrm{Y}$ or Sc and Kagomé ordering of the $\mathrm{Al}$ atoms. Further theoretical analysis suggests that the formation of $i$-MAB phases requires a significant difference in size for the two metals and demonstrates a new family of quaternary MABphase alloys. Moreover, the approach is expected to be applicable for other hexagonal materials and thus offers opportunities for more versatile chemistry and, in turn, the property tuning of functional materials.

\section{THEORETICAL AND EXPERIMENTAL DETAILS}

2.1. Density Functional Theory Calculations. All firstprinciples calculations were performed by means of density functional theory (DFT) and the projector augmented wave method, ${ }^{19,20}$ as implemented within the Vienna ab initio simulation package (VASP), version 5.4.1. ${ }^{21-23}$ We used the generalized gradient approximation (GGA) as parametrized by Perdew-Burke-Ernzerhof $(\mathrm{PBE})^{24}$ to treat the electron exchange and correlation effects. For phases with $\mathrm{Cr}, \mathrm{Mn}, \mathrm{Fe}$, and $\mathrm{Co}$, we used the spin-polarized GGA version with multiple spin configurations considered. The presented results are for the lowest-energy spin configuration. A plane-wave energy cutoff of $400 \mathrm{eV}$ was used, and the Brillouin zone was integrated by Monkhorst-Pack special $k$-point sampling with a $2 \pi \times 0.05 \AA^{-1} k$ point density in reciprocal space. ${ }^{25}$ The convergence of energy and structure with respect to the $k$-point density is shown in Figure S1. The total energy is minimized through the relaxation of the unit-cell shape and volume and internal atomic positions until satisfying an energy convergence of $10^{-6} \mathrm{eV} /$ atom and a force convergence of $10^{-2}$ $\mathrm{eV} / \mathrm{A}$. Visualization of the atomic structures was done with the VESTA code. $^{26}$

2.2. Structural Search for Chemical Order and Disorder. To investigate alloying trends within the M-sublattice of $\mathrm{M}_{2-x}{ }_{2} \mathrm{M}^{\prime \prime}{ }_{x} \mathrm{AlB}_{2}$, we used a theoretical approach based on the MIT ab initio phase stability (MAPS) ${ }^{27}$ code as implemented in the alloy theoretic automated tool kit (ATAT), ${ }^{28}$ within a high-throughput density functional theory (DFT) framework. In addition, the chemical disorder of $\mathrm{M}^{\prime}$ and $\mathrm{M}^{\prime \prime}$ has been modeled on the $\mathrm{M}$ sublattice using the special quasi-random structure (SQS) method. ${ }^{29}$ Convergence tests show that supercells with 120 atoms or more give a qualitatively accurate representation and a quantitative convergence in terms of calculated formation enthalpies, equilibrium volumes, and lattice parameters.

2.3. Stability Predictions. In this work, we have considered the alloying of $\mathrm{M}^{\prime}$ and $\mathrm{M}^{\prime \prime}$ from group 3 to 9: $\mathrm{Sc}, \mathrm{Y}, \mathrm{Ti}, \mathrm{Zr}, \mathrm{Hf}, \mathrm{V}, \mathrm{Nb}, \mathrm{Ta}$, $\mathrm{Cr}, \mathrm{Mo}, \mathrm{W}, \mathrm{Mn}, \mathrm{Fe}$, and Co considering orthorhombic and hexagonal structures of $\mathrm{M}_{2} \mathrm{AlB}_{2}$. The thermodynamic stability has been investigated at $0 \mathrm{~K}$ with respect to decomposition into any combination of competing phases. The most competitive set of competing phases, denoted the equilibrium simplex, is identified using a linear optimization procedure ${ }^{30,31}$ which has already been proven to be successful in confirming experimental materials as well as predicting the existence of new ones. ${ }^{3-36}$ The stability of a phase is quantified in terms of the formation enthalpy $\Delta H_{\mathrm{cp}}$ by comparing its energy to the energy of the equilibrium simplex according to

$$
\Delta H_{\text {cp }}=E\left(\mathrm{M}_{2-x}^{\prime} \mathrm{M}^{\prime \prime}{ }_{x} \mathrm{AlB}_{2}\right)-E \text { (equilibrium simplex) }
$$

A phase is concluded to be stable when $\Delta H_{c p}<0$. Here $E\left(\mathrm{M}_{2-x}^{\prime} \mathrm{M}^{\prime \prime}{ }_{x} \mathrm{AlB}_{2}\right)$ represents the chemical order of lowest energy, being the chemically ordered $\mathrm{M}_{4 / 3}^{\prime} \mathrm{M}^{\prime \prime}{ }_{2 / 3} \mathrm{AlB}_{2}$ or the disordered $\left(\mathrm{M}^{\prime}{ }_{0.67} \mathrm{M}^{\prime \prime}{ }_{0.33}\right)_{2} \mathrm{AlB}_{2}$. When $T \neq 0 \mathrm{~K}$, the contribution from configurational entropy resulting from a disordered distribution of $\mathrm{M}^{\prime}$ and $\mathrm{M}^{\prime \prime}$ on the $\mathrm{M}$ sublattice in $\left(\mathrm{M}_{0.67}^{\prime} \mathrm{M}^{\prime \prime}{ }_{0.33}\right)_{2} \mathrm{AlB}_{2}$ will decrease the Gibbs free energy $\Delta G_{\mathrm{cp}}^{\text {disorder }}$ as approximated by

$$
\Delta G_{\mathrm{cp}}^{\text {disorder }}[T]=\Delta H_{\mathrm{cp}}^{\text {disorder }}-T \Delta S
$$

where the entropic contribution $\Delta S$, assuming an ideal solution of $\mathrm{M}^{\prime}$ and $\mathrm{M}^{\prime \prime}$ on the $\mathrm{M}$ site, is given by

$$
\Delta S=-2 k_{\mathrm{B}}[y \ln (y)+(1-y) \ln (1-y)]
$$

where $k_{\mathrm{B}}$ is the Boltzmann constant and $y$ is the concentration of $\mathrm{M}^{\prime \prime}$ on the $\mathrm{M}$ sublattice.

2.4. Synthesis of Materials. The powders used herein were B (99.999\% Sigma-Aldrich), Mo (99.99\% Sigma-Aldrich), Al (99.8\% Alfa Aesar), Sc (99.99\% Stanford Advanced Material), and Y (99.9\% Alfa Aesar). To obtain the $\mathrm{Mo}_{4 / 3} \mathrm{Sc}_{2 / 3} \mathrm{AlB}_{2}$ and $\mathrm{Mo}_{4 / 3} \mathrm{Y}_{2 / 3} \mathrm{AlB}_{2}$ powder samples, a stoichiometric amount was mixed in an agate mortar, heated to $1400{ }^{\circ} \mathrm{C}$ in an alumina crucible under flowing argon, and held at that temperature for $8 \mathrm{~h}$. After this, the sample was cooled to $\mathrm{RT}$ in the furnace and a loosely packed powder was obtained. The powder was crushed and sieved through a 200 mesh sieve (particle size $74 \mu \mathrm{m}$ ). This fine powder was then used for XRD, EDX, and STEM.

2.5. Characterization of Materials. XRD scans of the $\mathrm{Mo}_{4 / 3} \mathrm{Sc}_{2 / 3} \mathrm{AlB}_{2}$ and $\mathrm{Mo}_{4 / 3} \mathrm{Y}_{2 / 3} \mathrm{AlB}_{2}$ powders were carried out on a diffractometer (Panalytical X'pert). The XRD diffractogram of the $\mathrm{Mo}_{4 / 3} \mathrm{Sc}_{2 / 3} \mathrm{AlB}_{2}$ and $\mathrm{Mo}_{4 / 3} \mathrm{Y}_{2 / 3} \mathrm{AlB}_{2}$ powders was analyzed by the Rietveld refinement method using the FULLPROF code. ${ }^{37,38}$ Refined parameters were the background parameters, zero shift, scale factors, $X$ and $Y$ profile parameters for peak shape, lattice parameters, and atomic positions for all phases.

Compositional analysis was carried out using energy-dispersive $\mathrm{X}$ ray spectroscopy (Oxford Instrument) on individual $\mathrm{Mo}_{4 / 3} \mathrm{Sc}_{2 / 3} \mathrm{AlB}_{2}$ and $\mathrm{Mo}_{4 / 3} \mathrm{Y}_{2 / 3} \mathrm{AlB}_{2}$ grains.

For the in-plane-ordered $\mathrm{Mo}_{4 / 3} \mathrm{Sc}_{2 / 3} \mathrm{AlB}_{2}$ and $\mathrm{Mo}_{4 / 3} \mathrm{Y}_{2 / 3} \mathrm{AlB}_{2}$ analyses, STEM combined with high-angle annular dark-field imaging (STEM-HAADF) and SAED was performed in the double-corrected Linköping FEI $\operatorname{Titan}^{3} 60-300$ operated at $300 \mathrm{kV}$. Fine powder was dispersed onto standard holey amorphous carbon support films suspended by $\mathrm{Cu}$ grids (SPI Supplies). Simulated SAED patterns were generated by CrystalDiffract in the CrystalMaker package.

\section{RESULTS}

3.1. Phase Stability of Ternary $\mathrm{M}_{2} \mathrm{AlB}_{2}$. The thermodynamic phase stability of the ternary $\mathrm{M}_{2} \mathrm{AlB}_{2}$ phases are evaluated by assuming both polymorphs: orthorhombic $\mathrm{Cmmm}$ (Figure 1a) and hexagonal $P \overline{6} \mathrm{~m} 2$ (Figure 1b) symmetry. Note that the Cmmm structure contains zigzag chains of boron while $P \overline{6} \mathrm{~m} 2$ has boron in a flat honeycomb lattice. Figure $1 \mathrm{c}$ shows the calculated formation enthalpy $\Delta H_{c p}$ at $0 \mathrm{~K}$ for $\mathrm{M}_{2} \mathrm{AB}_{2}$, with the corresponding identified equilibrium simplex listed in Table S1. The polymorphic crystal structure of lowest energy is identified and indicated in 


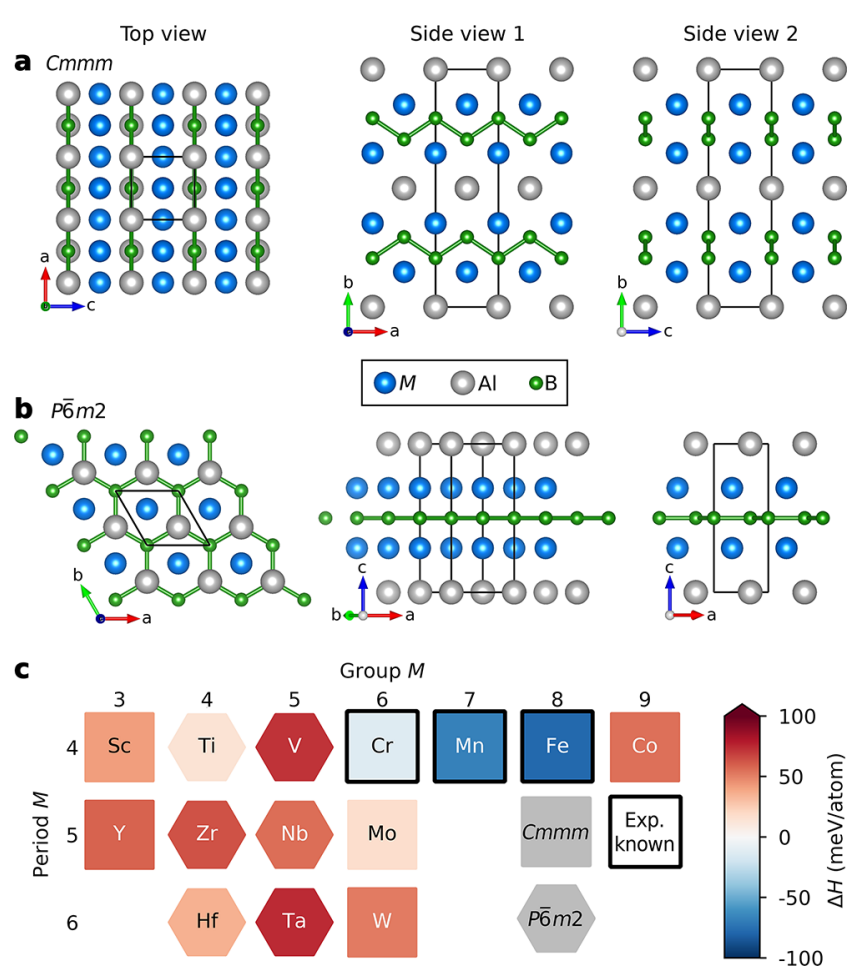

Figure 1. Phase stability of ternary $\mathrm{M}_{2} \mathrm{AlB}_{2}$. Schematic illustration of $\mathrm{M}_{2} \mathrm{AlB}_{2}$ with (a) orthorhombic Cmmm and (b) hexagonal $P \overline{6} \mathrm{~m} 2$ symmetry with unit cells marked by black lines. (c) Calculated theoretical phase stability for $\mathrm{M}_{2} \mathrm{AlB}_{2}$, identifying whether $\mathrm{Cmmm}$ (square) or $\bar{P} \overline{6} \mathrm{~m} 2$ (hexagon) is lowest in energy. Experimentally known phases are marked with a black box.

the figure through the displayed form. Only three $\mathrm{M}_{2} \mathrm{AlB}_{2}$ phases are found to be thermodynamically stable: $\mathrm{Cmmm}$ with $\mathrm{M}=\mathrm{Cr}, \mathrm{Mn}$, and $\mathrm{Fe}$. This is consistent with experimentally known phases $\left(\mathrm{Cr}_{2} \mathrm{AlB}_{2},{ }^{39} \mathrm{Mn}_{2} \mathrm{AlB}_{2},{ }^{10}\right.$ and $\left.\mathrm{Fe}_{2} \mathrm{AlB}_{2}{ }^{40}\right)$ and demonstrates that the predictive thermodynamic phase stability calculations for these types of materials is reliable. Moreover, the hexagonal structure is lowest in energy only for $\mathrm{M}$ from groups 4 and 5 but is found not to be stable $\left(\Delta H_{\mathrm{cp}}>\right.$ 0 ). $\mathrm{Ti}_{2} \mathrm{AlB}_{2}$ is close to being stable at $\Delta H_{\mathrm{cp}}=+14 \mathrm{meV} / \mathrm{atom}$, consistent with the theoretical results in ref 11 .

3.2. Identification of Structures with In-Plane Chemical Order upon Metal Alloying. With the exception of one theoretical report on the possible out-of-plane chemical order in $\mathrm{M}_{3} \mathrm{AlB}_{4}{ }^{18}$ there is no study on the chemical order in $\mathrm{MAB}$ phases and their alloys. We have therefore investigated M-site alloying of $\mathrm{M}_{2} \mathrm{AlB}_{2}$ considering the orthorhombic $\mathrm{C} m m m$ and hexagonal $P \overline{6} \mathrm{~m} 2$ structures. To reveal trends and possible chemical order, we have used the alloy theoretic automated tool kit (ATAT) to generate $\sim 1200$ chemically ordered candidate structures for each material system. Each individual structure was completely relaxed. In addition, we also considered structures with chemical disorder for $\mathrm{M}^{\prime}$ and $\mathrm{M}^{\prime \prime}$. As an example, Figure $2 \mathrm{a}-\mathrm{d}$ shows the calculated energy difference $\Delta E$ of $\mathrm{M}_{2-x}^{\prime} \mathrm{M}^{\prime \prime}{ }_{x} \mathrm{AlB}_{2}$ with respect to the ternary $\mathrm{M}_{2}{ }_{2} \mathrm{AlB}_{2}$ and $\mathrm{M}^{\prime \prime}{ }_{2} \mathrm{AlB}_{2}$ phases for two sets of $\mathrm{M}^{\prime}+\mathrm{M}^{\prime \prime}$ : $\mathrm{Sc}+$ Mo and V + Cr. For the chemically disordered structures, we also include the contribution from configurational entropy for an approximated synthesis temperature of $2000 \mathrm{~K}$. For $\mathrm{V}_{2-x} \mathrm{Cr}_{x} \mathrm{AlB}_{2}$, both the orthorhombic and hexagonal phases show a strong preference for chemical disorder at all $x$, as concluded from the ordered candidate structures being at higher energy as compared to the disordered structures when an entropy contribution at $2000 \mathrm{~K}$ is considered. There is also a rather small spread in energy for the ordered candidates.

For $\mathrm{Sc}_{2-x} \mathrm{Mo}_{x} \mathrm{AlB}_{2}$, there is a larger spread in $\Delta E$. For the $\mathrm{Cmmm}$ structure, most chemically ordered configurations have $\Delta E>0$, while for $P \overline{6} m 2$, all are negative $(\Delta E<0)$. A comparison of chemically ordered and disordered structures, when also including a contribution from the configurational entropy, reveals that only the hexagonal system prefers chemical ordering, with low-energy candidate structures for $0.5 \leq x \leq 4 / 3$. Of special interest are three configurations at $x$ $=4 / 3$, namely, those of $P \overline{6} 2 c, R \overline{3} \mathrm{~m}$, and $C 2$ symmetries. A similar structure with $P \overline{6} 2 c$ symmetry is found $40 \mathrm{meV} /$ atom higher in energy. These four ordered structures are schematically visualized in Figure $2 \mathrm{e}-\mathrm{h}$ and all have a characteristic arrangement with $\mathrm{M}^{\prime}$ situated in a honeycomb lattice and $\mathrm{M}^{\prime \prime}$ positioned in the center of the hexagon forming a triangular lattice. The minority $\mathrm{M}^{\prime \prime}$ is extended out from the $\mathrm{M}$ layer toward the $\mathrm{Al} \mathrm{layer}$, in turn displaying an ideal Kagomé lattice. The boron layers are hexagonal. A comparison of the in-plane ordered structures with the original ternary $P \overline{6} m 2$ structure is shown in Figure S2. Phonon calculations of the chemically ordered $\mathrm{Mo}_{4 / 3} \mathrm{Sc}_{2 / 3} \mathrm{AlB}_{2}$ with $P \overline{6} 2 m, P \overline{6} 2 c, R \overline{3} m$, and $\mathrm{C} 2$ symmetries reveal that they are all dynamically stable (Figures S3-S6). The in-plane ordered structure in Figure $2 \mathrm{e}-\mathrm{h}$ shows a close resemblance to $i$-MAX phases. ${ }^{6,7}$ Consequently, we choose to collectively denote the in-plane-ordered MAB phases as $i$-MAB.

3.3. Phase Stability Screening of Metal Alloys $\mathbf{M}^{\prime}{ }_{2-x} \mathbf{M}^{\prime \prime}{ }_{x} \mathbf{A l B}_{2}$. For an evaluation of the phase stability of $\mathrm{M}_{2-x}^{\prime} \mathrm{M}^{\prime \prime}{ }_{x} \mathrm{AlB}_{2}\left(\left\{\mathrm{M}^{\prime}, \mathrm{M}^{\prime \prime}\right\}=\mathrm{Sc}, \mathrm{Y}, \mathrm{Ti}, \mathrm{Zr}, \mathrm{Hf}, \mathrm{V}, \mathrm{Nb}, \mathrm{Ta}, \mathrm{Cr}\right.$, $\mathrm{Mo}, \mathrm{W}, \mathrm{Mn}, \mathrm{Fe}$, and $\mathrm{Co}$ ), we make two assumptions based on the result presented in Figure 2: (i) for the orthorhombic $\mathrm{Cmmm}$ structure, only disorder is considered, while (ii) for the hexagonal systems, disorder in the $\bar{P} \overline{6} \mathrm{~m} 2$ symmetry is considered along with identified ordered $i$-MAB candidates $P \overline{6} 2 m, P \overline{6} 2 c, R \overline{3} m$, and $C 2$. It should be noted that modeling disorder in any of the four identified ordered structures yields results similar to those for $P \overline{6} m 2$ upon relaxation.

In Figure 3, an overview of the preferred chemical order (crystal symmetry) or disorder is shown for the 182 unique combinations of $\mathrm{M}^{\prime}$ and $\mathrm{M}^{\prime \prime}$. The trends in thermodynamic stability are visualized using a heat map, where $\mathrm{M}^{\prime}$ and $\mathrm{M}^{\prime \prime}$ are listed on the basis of the metal's periodic group. The background color represents the calculated thermodynamic stability for the chemically ordered/disordered configuration of lowest energy, with the blue region representing stable phases $\left(\Delta H_{\mathrm{cp}}\right.$ or $\left.\Delta G_{\mathrm{cp}}<0\right)$. We also use a symbol representation to denote the structure of lowest energy: $\mathrm{Cmmm}$ with disorder (open squares), $P \overline{6} \mathrm{~m} 2$ with disorder (open hexagons), $i-\mathrm{MAB}$ phases with $P \overline{6} 2 \mathrm{~m}$ (filled hexagons), $P \overline{6} 2 \mathrm{c}$ (filled left triangles), $R \overline{3} m$ (filled up triangles), and $\mathrm{C} 2$ (filled down triangles) symmetries. In addition, experimentally known quaternary phases are marked by a green square. Identified equilibrium simplexes are listed in Table $\mathrm{S} 2$ for all combinations of $\mathrm{M}^{\prime}$ and $\mathrm{M}^{\prime \prime}$.

Figure $3 \mathrm{a}$ depicts the calculated formation enthalpy at $0 \mathrm{~K}$ showing that a majority, 132, of the 182 elemental combinations of $\mathrm{M}^{\prime}$ and $\mathrm{M}^{\prime \prime}$ are ordered in a hexagonal structure. Out of these, 15 are stable $\left(\Delta H_{c p}<0\right)$, with $\mathrm{M}^{\prime}$ mainly coming from groups 6 to $8(\mathrm{Cr}, \mathrm{Mo}, \mathrm{W}, \mathrm{Mn}$, and $\mathrm{Fe})$ combined with $\mathrm{M}^{\prime \prime}$ from group 3 ( $\mathrm{Sc}$ and $\mathrm{Y}$ ). Of the four considered ordered structures, six systems have $R \overline{3} m$ 

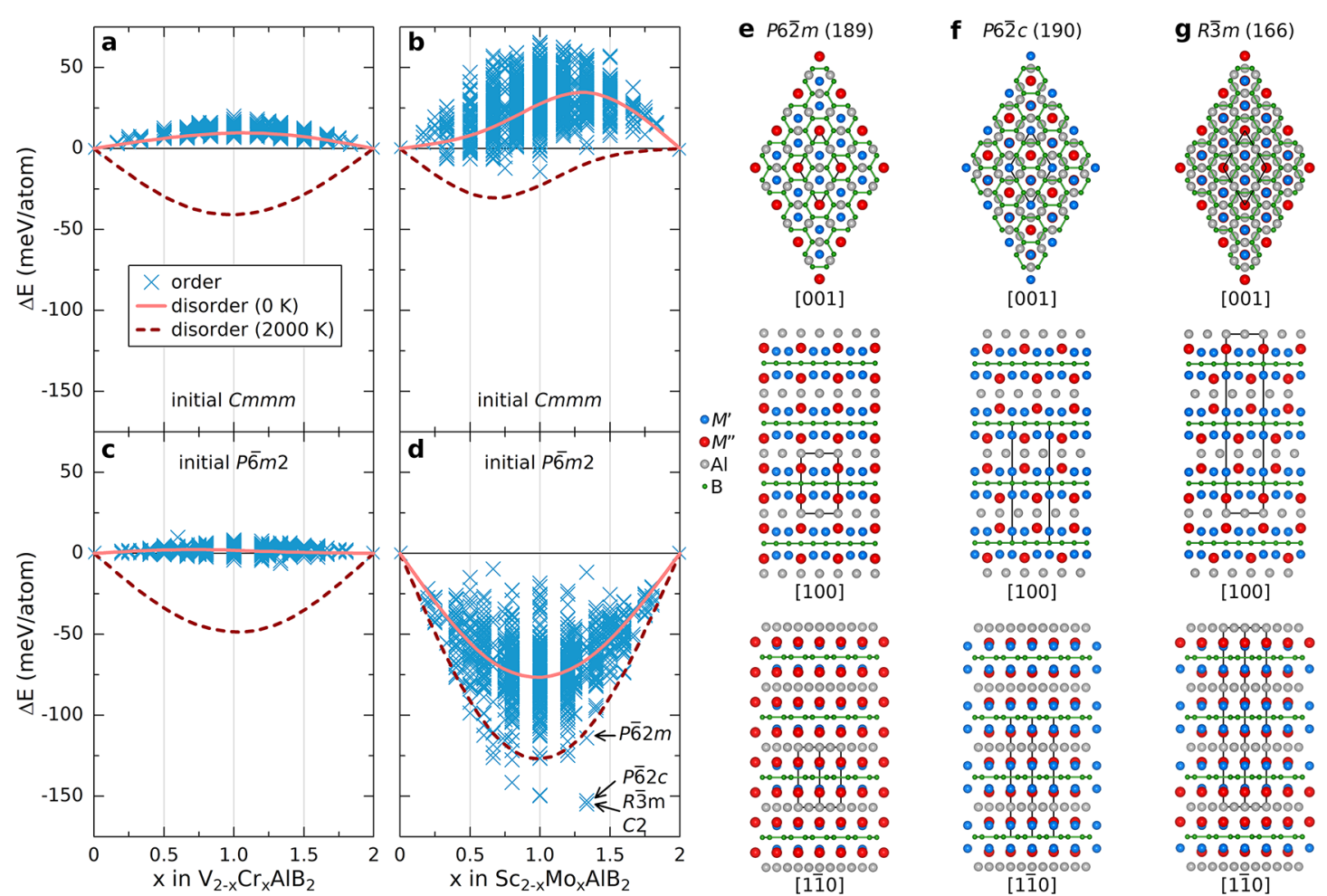

h $\quad C 2(5)$
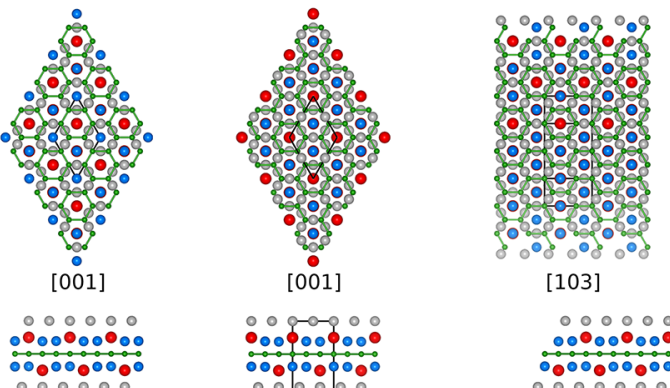

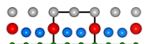
0 $\therefore 0000$. $\because 000000$

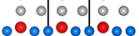
$\therefore$ $000 \%$

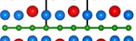

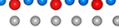
[100]

00000000000

000000

000000.

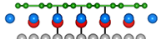

- 0 .

001000.

0 .

00000 .

[110]

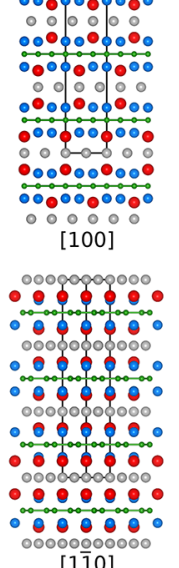

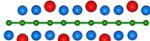
잉 0000000 - oroorode. 0500000 $20-\infty-\infty$ 0000000000 $\therefore$ 0000000

$$
\text { [010] }
$$

0000000000000 $0000-000$ 0000000000000 $-00-000$ 000 - 00000 $-\infty-\infty$ - 10 $\infty-\infty-\infty-\infty$

[100]

Figure 2. Identification of structures with chemical order. Calculated energy difference between $\mathrm{M}^{\prime}{ }_{2-x} \mathrm{M}^{\prime \prime}{ }_{x} \mathrm{AlB}_{2}$ and corresponding ternaries $\mathrm{M}^{\prime}{ }_{2} \mathrm{AlB}_{2}$ and $\mathrm{M}^{\prime \prime}{ }_{2} \mathrm{AlB}_{2}$ at $0 \mathrm{~K}$ as a function of $x$ for chemically ordered $(\mathrm{X})$ and disordered (solid line) candidate structures, assuming (a and $\mathrm{b}$ ) $\mathrm{Cmmm}$ and (c and d) $P \overline{6} \mathrm{~m} 2$ symmetry of $\mathrm{M}_{2-x}^{\prime} \mathrm{M}^{\prime \prime}{ }_{x} \mathrm{AlB}_{2}$ for $\mathrm{M}^{\prime}+\mathrm{M}^{\prime \prime}$ being (a and c) $\mathrm{V}+\mathrm{Cr}$ and (b and d) Sc + Mo. For chemical disorder, the entropy contribution to the Gibbs free energy at $2000 \mathrm{~K}$ has also been approximated (dashed line). Comparison of different in-plane chemically ordered candidate structures and a schematic illustration of four stacking sequences identified for $\mathrm{Mo}_{4 / 3} \mathrm{Sc}_{2 / 3} \mathrm{AlB}_{2}$ with (e) $P \overline{6} 2 \mathrm{~m}$, (f) $P \overline{6} 2 c$, (g) $R \overline{3} m$, and (h) $C 2$ symmetry along three zone axes. The unit cells are marked by black lines.

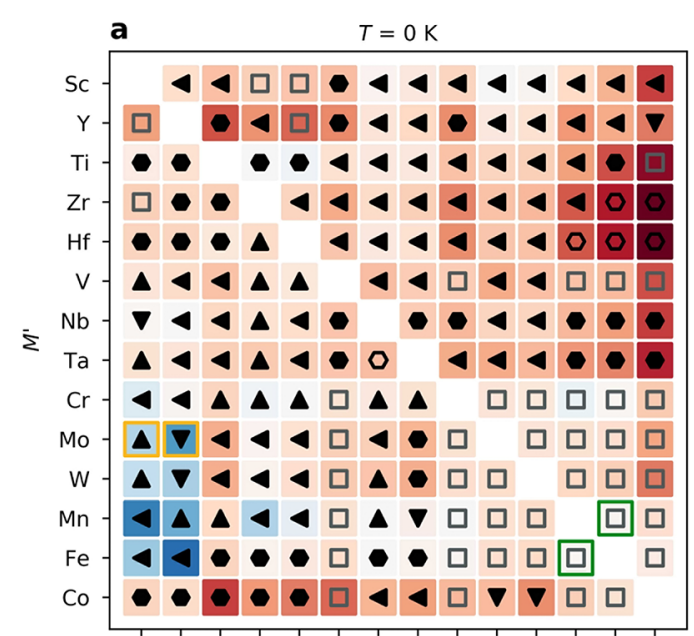

Sc Y Ti Zr Hf $V$ Nb Ta Cr Mo W Mn Fe Co $M^{\prime \prime}$

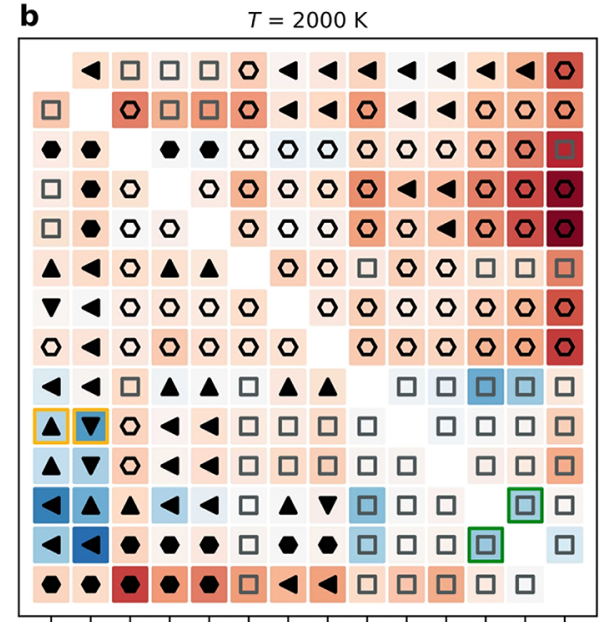

Sc Y Ti Zr Hf $\mathrm{V}$ Nb Ta Cr Mo W Mn Fe Co M"

Figure 3. Predicted phase stability for $\mathrm{M}_{4 / 3}^{\prime} \mathrm{M}^{\prime \prime}{ }_{2 / 3} \mathrm{AlB}_{2}$ alloys. (a) Calculated formation enthalpy at $0 \mathrm{~K}$ and (b) Gibbs free energy of formation at $2000 \mathrm{~K}$. Symbols represent the crystal structure and chemical order of lowest energy for a given $\mathrm{M}^{\prime}$ and $\mathrm{M}_{-}^{\prime \prime}$ : Cmmm with disorder (open squares), $P \overline{6} m 2$ with disorder (open hexagons), and in-plane-ordered $i$-MAB phases with $P \overline{6} 2 m$ (filled hexagons), $P \overline{6} 2 c$ (filled left triangles), $R \overline{3} m$ (filled up triangles), and C2 (filled down triangles) symmetries. Experimentally known phases are marked with squares: green (prior to this work) and yellow (this work).

symmetry, six have $P \overline{6} 2 c$ symmetry, two have $C 2$ symmetry, and only one has $P \overline{6} 2 m$ symmetry. It should be noted that $R \overline{3} \mathrm{~m}, P \overline{6} 2 c$, and $C 2$ are close in energy, within a few $\mathrm{meV} /$ atom, as they are structurally similar on a short-range scale. Another 13 ordered phases are close to stable, or metastable (0 $<\Delta H_{\text {cp }}<+25 \mathrm{meV} /$ atom).
For $\mathrm{M}_{2} \mathrm{AlB}_{2}$ and $\left(\mathrm{Fe}_{2-x} \mathrm{Mn}_{x}\right)_{5} \mathrm{AlB}_{2}$ phases, synthesis is typically performed in the range from 1000 to $1600{ }^{\circ} \mathrm{C}$ (1273 to $1873 \mathrm{~K})$. To account for the contribution from configurational entropy to the Gibbs free energy at such temperatures, we use eqs 2 and 3 for the structures modeled with a disordered distribution of $\mathrm{M}^{\prime}$ and $\mathrm{M}^{\prime \prime}$ (SQS). We 

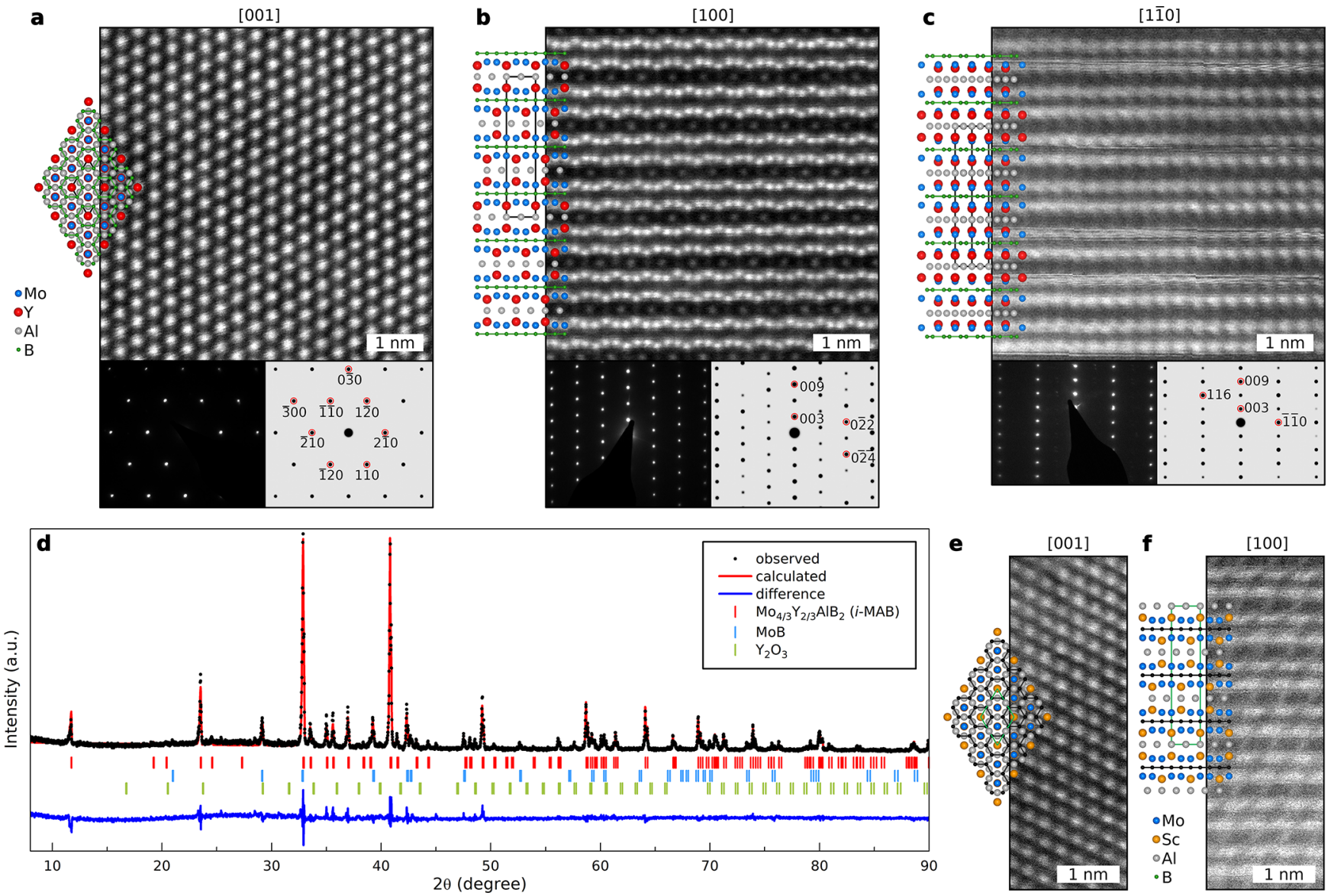

Figure 4. Characterization of synthesized $\mathrm{Mo}_{4 / 3} \mathrm{Y}_{2 / 3} \mathrm{AlB}_{2}$ and $\mathrm{Mo}_{4 / 3} \mathrm{Sc}_{2 / 3} \mathrm{AlB}_{2} i-\mathrm{MAB}$ phases. (a-c) In-plane chemical ordering of the $i$-MAB phase is evident from HRSTEM images along the [001], [100], and [110] zone axes, respectively, with corresponding measured (left) and simulated (right) selected-area electron diffraction (SAED). Schematics to the left of each image represent the corresponding atomic arrangements considering the hexagonal $R \overline{3} m$ (no. 166) structure. (d) Rietveld refinement of XRD of the sample assuming space group $R \overline{3} m$ (no. 166). (e and f) In-plane chemical ordering of the $\mathrm{Mo}_{4 / 3} \mathrm{Sc}_{2 / 3} \mathrm{AlB}_{2} \mathrm{i}-\mathrm{MAB}$ phase as evident from HRSTEM images along the [001] and [100] zone axes, respectively.

choose $2000 \mathrm{~K}$ as a representative temperature. The heat map in Figure $3 \mathrm{~b}$ is constructed by comparing $\Delta H_{\mathrm{cp}}$ of the chemically ordered candidate structures with $\Delta G_{\mathrm{cp}}$ of the disordered $C m m m$ and $P \overline{6} \mathrm{~m} 2$, with colors and symbols used in line with Figure 3a.

At $2000 \mathrm{~K}$, the number of chemically ordered and stable $\mathrm{M}_{4 / 3}^{\prime} \mathrm{M}^{\prime \prime}{ }_{2 / 3} \mathrm{AlB}_{2}$ phases is equal to the number identified at 0 $\mathrm{K}$. This indicates that these 15 chemically ordered phases are not only thermodynamically stable with respect to the competing phases but also sufficiently stable toward the formation of chemical disorder at typical synthesis temperatures. This is a key result in the search for experimentally verifiable chemically ordered $\mathrm{MAB}$ phases.

Moreover, at $2000 \mathrm{~K}$, the number of stable disordered phases has increased from 1 to 16 . These are mainly found for the $\mathrm{Cmmm}$ structure, 14 out of 16 , with combinations of $\mathrm{M}$ and $\mathrm{M}^{\prime \prime}$ being $\mathrm{Cr}, \mathrm{Mn}, \mathrm{Fe}$, and $\mathrm{Co}$. The latter includes the experimentally reported $\mathrm{Fe}_{2-x} \mathrm{Mn}_{x} \mathrm{AlB}_{2}\left(x=0.67\right.$ and 1.33). ${ }^{15}$ In addition, 13 ordered and 17 disordered phases are found to be close to stable or metastable $\left(0<\Delta H_{\mathrm{cp}}\right.$ or $\Delta G_{\mathrm{cp}}<+25$ $\mathrm{meV} /$ atom). The additional disordered phases are primarily $\mathrm{Cmmm}$ with combinations of $\mathrm{M}^{\prime}$ and $\mathrm{M}^{\prime \prime}$ from groups 6 to 8 .

$i$-MAB is characterized by a $2: 1$ ratio of $\mathrm{M}^{\prime} / \mathrm{M}^{\prime \prime}$ and a size difference where $\mathrm{M}^{\prime \prime}$ should be at least $0.2 \AA$ larger than $\mathrm{M}^{\prime}$. This is illustrated in Figure S11a, showing the calculated $\Delta H$ and $\Delta G$ (also indicated in Figure $3 \mathrm{~b}$ ) as a function of the atomic size difference between $\mathrm{M}^{\prime \prime}$ and $\mathrm{M}^{\prime}$. Most of the structures with a preference for chemical order (i.e., the $i-\mathrm{MAB}$ phases) display this size difference. This is in contrast to the identified preferred $\mathrm{Cmmm}$ structures with chemical disorder, where the size difference between $\mathrm{M}^{\prime}$ and $\mathrm{M}^{\prime \prime}$ is within $\pm 0.2 \AA$. Correspondingly, $P \overline{6} \mathrm{~m} 2$ with disorder is preferred for $-0.6<$ $r_{\mathrm{M}^{\prime \prime}}-r_{\mathrm{M}^{\prime}}<+0.2 \AA$. Compared to the ternary $\mathrm{M}_{2} \mathrm{AlB}_{2}$ phases, the large difference in atomic radius of $\mathrm{M}^{\prime}$ and $\mathrm{M}^{\prime \prime}$ in $i-\mathrm{MAB}$ induces a change in the out-of-plane coordinates for $\mathrm{M}^{\prime \prime}$ toward the $\mathrm{Al}$ layer, which in turn induces a change in the $\mathrm{Al}$ layer to form an ideal Kagomé lattice. The impact from the electronegativity of $\mathrm{M}^{\prime}$ and $\mathrm{M}^{\prime \prime}$ (Figure S11b) does not show as clear a correlation as found for the size difference between $\mathrm{M}^{\prime}$ and $\mathrm{M}^{\prime \prime}$. This in line with the common features reported for $i$-MAX phases. ${ }^{7,41}$

To summarize selected key results from the thermodynamic stability evaluation of $182 \mathrm{M}^{\prime}{ }_{2-x} \mathrm{M}^{\prime \prime}{ }_{x} \mathrm{AlB}_{2}$ phases, a preference for chemical order is found for a $2: 1$ ratio between the $M$ elements where $\mathrm{M}^{\prime \prime}$ is significantly larger than $\mathrm{M}^{\prime}(>0.2 \AA)$. In most cases, this is fulfilled when $M^{\prime}$ from groups 6 to 9 is combined with $\mathrm{M}^{\prime \prime}$ from group 3 ( $\mathrm{Sc}$ and $\mathrm{Y}$ ) and 4 ( $\mathrm{Zr}$ and $\mathrm{Hf})$. Of particular interest are eight ordered and thermodynamically stable candidates, $\mathrm{M}_{4 / 3}^{\prime} \mathrm{M}^{\prime \prime}{ }_{2 / 3} \mathrm{AlB}_{2}$ where $\mathrm{M}^{\prime}=\mathrm{Mo}$, $\mathrm{W}, \mathrm{Mn}$, and $\mathrm{Fe}$ and $\mathrm{M}^{\prime \prime}=\mathrm{Sc}$ and $\mathrm{Y}$, which allows systematic 
compositional alterations. However, $\mathrm{M}^{\prime}=\mathrm{Ti}, \mathrm{Cr}$, and $\mathrm{Mn}$ and $\mathrm{M}^{\prime \prime}=\mathrm{Zr}, \mathrm{Hf}$, and $\mathrm{Nb}$ are also fundamentally interesting, potentially expanding the elemental space and consequently the properties of these borides.

3.4. Synthesis and Characterization of Chemically Ordered $i$-MAB Phases. Out of the 15 ordered and stable $i$ $\mathrm{MAB}$ phases predicted in Figure $3 \mathrm{~b}$, bulk synthesis was attempted for $\mathrm{Mo}_{4 / 3} \mathrm{Y}_{2 / 3} \mathrm{AlB}_{2}$ and $\mathrm{Mo}_{4 / 3} \mathrm{Sc}_{2 / 3} \mathrm{AlB}_{2}$ by the solidstate reaction of a stoichiometric amount of elemental powder. The choice of $\mathrm{M}^{\prime}$ as $\mathrm{Mo}$ and $\mathrm{M}^{\prime \prime}$ as $\mathrm{Y}$ and $\mathrm{Sc}$ was motivated by their predicted stability, thermodynamic (Figure 3) and dynamic (Figures S3-S10), and the identified large size difference between Mo and Y/Sc.

High-resolution scanning transmission electron microscopy (HRSTEM) images of the $\mathrm{Mo}_{4 / 3} \mathrm{Y}_{2 / 3} \mathrm{AlB}_{2} i$-MAB phase along [001], [100], and [1 $1 \overline{1} 0]$ zone axes are shown in Figure $4 a-c$, respectively. For the applied imaging conditions, the Mo and $\mathrm{Y}$ atoms are the brightest, the $\mathrm{Al}$ atoms are less bright, and $\mathrm{B}$ is too light to be visible. The schematics to the left of each micrograph show the atomic arrangements expected, assuming hexagonal $\mathrm{Mo}_{4 / 3} \mathrm{Y}_{2 / 3} \mathrm{AlB}_{2}$ in space group $R \overline{3} m$ (no. 166).

From the top view in Figure $4 \mathrm{a}$, the hexagonal structure is evident. Along the $[1 \overline{1} 0]$ zone axis (Figure $4 \mathrm{c}$ ), Mo and $\mathrm{Y}$ are superimposed, resulting in an average contrast strongly resembling $\mathrm{M}_{2} \mathrm{AlB}_{2}$ in Figure $1 \mathrm{~b}$. Along the [100] zone axis (Figure 4b), a "buckled" $M$ layer consisting of a chemically ordered configuration of $\mathrm{Mo}$ and $\mathrm{Y}$ is indicated, with $\mathrm{Y}$ extending toward the $\mathrm{Al}$ layer. The relative contrast differences between Mo and Y are small, and the distinction between the two is not trivial. However, the suggested atomic arrangement is supported by the theoretical predictions and the indirect evidence from the $\mathrm{M}$ - and Al-layer interaction. Within the $\mathrm{Al}$ layer, spots of different contrast and spatial distribution are seen (Figure $4 \mathrm{~b}$ ) as a result of $\mathrm{M}^{\prime \prime}$ (most likely the larger $\mathrm{Y}$ atoms) being extended toward the Al layer, which in turn forms a Kagomé lattice, as also shown in the schematic representations in Figure S2. Furthermore, the in-planeordered $i-\mathrm{MAB}$ structure is also revealed by the measured and simulated selective area electron diffraction (SAED) shown in the insets of Figure $4 a-c$. Additional simulated SAEDs for all four polymorphs of $i-\mathrm{MAB}$ are shown in Figure S12. The structure based on space group $R \overline{3} m$ (no. 166) gives the best agreement with the experimental data.

The X-ray diffraction (XRD) pattern of a sample with nominal composition $\mathrm{Mo}_{4 / 3} \mathrm{Y}_{2 / 3} \mathrm{AlB}_{2}$ is shown in Figure $4 \mathrm{~d}$. Rietveld refinement based on space group $R \overline{3} m$ (no. 166) is also included in the graph, with the refinement parameters listed in Table S3. The lattice parameters calculated from the XRD Rietveld analysis, $a=5.44577(9) \AA$ and $c=$ 22.69048(38) $\AA$, are consistent with the theoretical values, $a$ $=5.462 \AA$ and $c=22.755 \AA$ (Table S4). The other ordered candidate structures were also considered, but with resulting lower-quality fitting to the XRD pattern. Figure S14 shows a comparison between the measured XRD pattern and the simulated diffractograms from the four relaxed (using DFT) $i$ $\mathrm{MAB}$ structures, disordered $\mathrm{Mo}_{4 / 3} \mathrm{Y}_{2 / 3} \mathrm{AlB}_{2}, \mathrm{Mo}_{2} \mathrm{AlB}_{2}$, and $\mathrm{Y}_{2} \mathrm{AlB}_{2}$ with $P \overline{6} m 2$ symmetry. The simulations further support space group $R \overline{3} m$ (no. 166) symmetry.

The metal ratios calculated from the energy-dispersive X-ray spectroscopy spectrum (EDX) are shown in Figure S13 with $\mathrm{Mo} / \mathrm{Y}$ and $(\mathrm{Mo}+\mathrm{Y}) / \mathrm{Al}$ atomic ratios of 1.9 and 2.0, respectively, which are very close to the ideal ratio of 2.0.
Material synthesis of $\mathrm{Mo}_{4 / 3} \mathrm{Sc}_{2 / 3} \mathrm{AlB}_{2}$ reveals the same $i-\mathrm{MAB}$ structure as found for $\mathrm{Mo}_{4 / 3} \mathrm{Y}_{2 / 3} \mathrm{AlB}_{2}$. The schematic illustration and high-resolution STEM (HRSTEM) images (Figure 4e,f and Figure S15) show that the in-plane chemical order is evident only along the [100] zone axis (Figure 4f) where the $\mathrm{M}$ layers consist of brighter spots that correspond to Mo, with those that are not as bright corresponding to Sc, extending slightly toward the $\mathrm{Al}$ layer. This extension is less pronounced compared to $\mathrm{Y}$ in $\mathrm{Mo}_{4 / 3} \mathrm{Y}_{2 / 3} \mathrm{AlB}_{2}$ since the size difference between Mo and $\mathrm{Sc}$ is smaller than that for Mo and Y. Along the $[1 \overline{1} 0]$ zone axis, a mixed contribution of both Mo and $\mathrm{Sc}$ atoms is seen. This orientation looks identical to the hexagonal $\mathrm{M}_{2} \mathrm{AlB}_{2}$ shown in Figure $1 \mathrm{~b}$. Rietveld refinement of the XRD pattern (Figure S15d) based on space group $R \overline{3} m$ (no. 166), with the refinement parameters listed in Table S5, suggests that the majority of the sample consists of the $i-\mathrm{MAB}$ phase. Corresponding lattice parameters calculated from the XRD Rietveld analysis, $a=5.36261(8) \AA$ and $c=$ $22.44267(42) \AA$, are consistent with the theoretical values, $a$ $=5.383$ and $c=22.384 \AA$ (Table S6). Calculated values are obtained at $0 \mathrm{~K}$, while XRD was performed at room temperature. Compositional analysis from EDX gives $\mathrm{Mo} / \mathrm{Sc}$ and $(\mathrm{Mo}+\mathrm{Sc}) / \mathrm{Al}$ ratios of 1.8 and 1.9 , respectively, close to the ideal ratio of 2.0. This is shown in Figure S13. The $i-M A B$ structure of $\mathrm{Mo}_{4 / 3} \mathrm{Sc}_{2 / 3} \mathrm{AlB}_{2}$ is further supported in Figure S16 when comparing the measured XRD pattern with simulated diffractograms of the four $i$-MAB structures, disordered $\mathrm{Mo}_{4 / 3} \mathrm{Sc}_{2 / 3} \mathrm{AlB}_{2}, \mathrm{Mo}_{2} \mathrm{AlB}_{2}$, and $\mathrm{Sc}_{2} \mathrm{AlB}_{2}$ with $P \overline{6} \mathrm{~m} 2$ symmetry. Note that the 110 peak in the XRD pattern at around $19.5^{\circ}$, corresponding to an interplanar distance of $4.5 \AA$, is a superstructure peak solely due to $\mathrm{Mo} / \mathrm{Sc}$ chemical ordering which could potentially be quite useful for the identification of other in-plane-ordered $212 \mathrm{MAB}$ phases. This 110 peak does not exist in the ternary $\mathrm{Mo}_{2} \mathrm{AlB}_{2}$ and $\mathrm{Sc}_{2} \mathrm{AlB}_{2}$ phases or in disordered $\mathrm{Mo}_{4 / 3} \mathrm{Sc}_{2 / 3} \mathrm{AlB}_{2}$. However, it should be noted that for the $\mathrm{Mo}_{4 / 3} \mathrm{Y}_{2 / 3} \mathrm{AlB}_{2} i-\mathrm{MAB}$ phase, the 110 peak is of too low an intensity to be visible, which implies that the 110 peak alone should not be used as a distinct fingerprint for claiming an $i$ $\mathrm{MAB}$ structure.

\section{DISCUSSION}

The family of atomically laminated boride-based ternary materials has crystal structures of tetragonal and orthorhombic symmetry. The recent discovery of $\mathrm{Ti}_{2} \mathrm{InB}_{2}$ by Wang et al. revealed the first laminated hexagonal structure. ${ }^{11}$ This hexagonal layered structure is composed of three elements, out of which one is a metal, which do not alone justify it to be classified as a MAX phase or grant an extension of the definition of MAX phases. The composition of hexagonal $\mathrm{Ti}_{2} \mathrm{InB}_{2}$ is analogous to general formula $(\mathrm{MB})_{z} \mathrm{~A}_{y}\left(\mathrm{MB}_{2}\right)_{x}$ of MAB phases (e.g., orthorhombic $\mathrm{Cr}_{2} \mathrm{AlB}_{2}$ and $\mathrm{Cr}_{3} \mathrm{AlB}_{4}$ ), which is different from the general $\mathrm{M}_{n+1} \mathrm{AX}_{n}$ composition of MAX phases. Furthermore, the $\mathrm{B}$ atoms in $\mathrm{Ti}_{2} \mathrm{InB}_{2}$ occupy Wyckoff sites $1 \mathrm{~b}$ and $1 \mathrm{f}$ with an $\mathrm{M}$ layer on each side, forming a honeycomb lattice with strong covalent $\mathrm{B}-\mathrm{B}$ bonding rather than a triangular lattice such as $\mathrm{X}$ in MAX phases. This is due to the $\mathrm{B} / \mathrm{Ti}$ ratio being 1 , which is greater than the $\mathrm{X} / \mathrm{M}$ ratios $(n /(n+1))$ in conventional MAX phases. In principle, the $\mathrm{Ti}_{2} \mathrm{InB}_{2}$ phase as such could be seen as an extension of the concept of MAX phases but should, in our view, not be considered to be part of the MAX phase family. It should be noted that boron-based MAX phases have recently been discovered by Rackl et al. ${ }^{42,43}$ 
A key requirement for obtaining chemical order upon metal alloying is an underlying hexagonal structure combined with a metal ratio $\mathrm{M}^{\prime} / \mathrm{M}^{\prime \prime}$ of $2: 1$ and a large enough size difference between the alloying metals. The hexagonal symmetry allows for relaxation of the Al layer into a perfect Kagomé lattice. This is a direct consequence of the larger $\mathrm{M}^{\prime \prime}$ ( $\mathrm{Y}$ and Sc herein) being displaced from the smaller $\mathrm{M}^{\prime}$ (Mo herein) toward the $\mathrm{Al}$ layer, which in turn rearranges the relatively loosely bonded $\mathrm{Al}$ atoms. This is illustrated in Figure S17. Such relaxation is not possible from a symmetry point of view in tetragonal and orthorhombic structures. The $2: 1 \mathrm{M}^{\prime} / \mathrm{M}^{\prime \prime}$ ratio is of particular importance since a hexagonal lattice further allows for chemical order, where the $\mathrm{M}^{\prime}$ lattice forms a honeycomb lattice combined with a hexagonal $\mathrm{M}^{\prime \prime}$ lattice. Note that the $\mathrm{Al}$ layer acts as a local mirror plane. Moreover, metal alloying allows for the inclusion of additional elements not found in the traditional $\mathrm{M}_{2} \mathrm{AlB}_{2}$ phases, as exemplified by $\mathrm{Y}$ and $\mathrm{Sc}$ for herein stable and verified $i$-MAB phases but also for predicted stable $i$-MAB phases with $\mathrm{Zr}, \mathrm{Hf}$, and $\mathrm{Nb}$ and disordered $\mathrm{MAB}$ phases with $\mathrm{V}, \mathrm{Nb}$, and $\mathrm{Ta}$. Furthermore, all of the four considered $i$-MAB candidates (with $P \overline{6} 2 m, P \overline{6} 2 c, R \overline{3} m$, and $C 2$ symmetries) are found to be dynamically stable, as shown for $\mathrm{Mo}_{4 / 3} \mathrm{Sc}_{2 / 3} \mathrm{AlB}_{2}$ and $\mathrm{Mo}_{4 / 3} \mathrm{Y}_{2 / 3} \mathrm{AlB}_{2}$ in Figures S3-S10. This indicates that the in-plane order of $\mathrm{M}^{\prime}$ and $\mathrm{M}^{\prime \prime}$, independent of different stackings, truly forms a stable structure and rules out some as-yet unobserved ordering phenomena stabilizing the synthesized material.

The herein reported discovery of a family of chemically ordered and atomically laminated boride alloys is profound and will from this point forward take inspiration from the hexagonal MAX phases and their $2 \mathrm{D}$ derivatives, MXenes. In 2017, metal alloying of a MAX phase revealed the first chemically ordered $i$-MAX phase, $\left(\mathrm{Mo}_{2 / 3} \mathrm{Sc}_{1 / 3}\right)_{2} \mathrm{AlC}{ }^{6}$ Since then, 32 different $i$-MAX phases have been realized experimentally. $^{6-8,41,44-51}$ Out of these, four have so far been converted to 2D MXenes, ${ }^{6,8,9,52-57}$ displaying properties that are highly promising for energy storage and catalysis. Most importantly, the 3D $i$-MAX phase alloys can be converted to $2 \mathrm{D}$ using the concept of "targeted etching", realizing either chemical ordering or vacancy ordering depending on the etching protocol.

The similarities between $i$-MAB and $i$-MAX phases are many, as illustrated in Figure S17. Both require a 2:1 $\mathrm{M}^{\prime} / \mathrm{M}^{\prime \prime}$ ratio, with $\mathrm{M}^{\prime \prime}$ being significantly larger than $\mathrm{M}^{\prime}$, to form inplane chemical order combining a honeycomb $\mathrm{M}^{\prime}$ lattice with a hexagonal $\mathrm{M}^{\prime \prime}$ lattice. Furthermore, the larger $\mathrm{M}^{\prime \prime}$ is displaced toward the $\mathrm{Al} / \mathrm{A}$ layer, which induces an ideal Kagomé lattice for $\mathrm{Al}$ in $i-\mathrm{MAB}$ and a Kagomé-like lattice for $\mathrm{A}$ in $i$-MAX. With the vast and recent exploration of $i$-MAX phases and corresponding 2D MXenes, we expect further exploration of $i$ MAB phases, which, combined with suitable etching protocols, constitutes an exciting and facile route toward designing novel $2 \mathrm{D}$ materials with unprecedented properties.

\section{CONCLUSIONS}

Herein, we have considered the traditional orthorhombic and a recently discovered hexagonal $\mathrm{M}_{2} \mathrm{AB}_{2}$ crystal structures to investigate the possibility of chemical ordering upon metal alloying of metal borides. Through cluster expansion, four crystal structures exhibiting in-plane chemical order are identified and denoted as $i$-MAB phases. Combined with high-throughput predictive stability theory, we reduce the 182 hypothetical combinations to 15 predicted chemically ordered and stable $i-\mathrm{MAB}$ phases. The theoretical predictions were verified for $\mathrm{Mo}_{4 / 3} \mathrm{Y}_{2 / 3} \mathrm{AlB}_{2}$ and $\mathrm{Mo}_{4 / 3} \mathrm{Sc}_{2 / 3} \mathrm{AlB}_{2}$, showing hexagonal $R \overline{3} m$ (no. 166) crystal symmetry consistent with the simulations. Furthermore, we also predict 16 disordered alloys, altogether expanding the elemental space of these borides with five elements ( $\mathrm{Sc}, \mathrm{Y}, \mathrm{Zr}, \mathrm{Hf}$, and $\mathrm{Nb}$ ) not previously used in the ternary counterparts. On the basis of the results shown herein, we have identified a family of chemically ordered boride alloys, and it is reasonable to believe that (i) more $i-\mathrm{MAB}$ phases will be discovered, (ii) they have a high potential for conversion to a $2 \mathrm{D}$ counterpart through the selective etching of $\mathrm{Al}$ and possibly the alloying element, in line with $i$-MAX phases and their MXenes, and (iii) our combined theoretical approach may be of importance in the identification of chemically ordered structure in other atomically laminated boride-based ternary materials and hexagonal materials in general when metal alloying is considered.

\section{ASSOCIATED CONTENT}

\section{SI Supporting Information}

The Supporting Information is available free of charge at https://pubs.acs.org/doi/10.1021/jacs.0c08113.

Crystallographic data for $\mathrm{Mo}_{4 / 3} \mathrm{Y}_{2 / 3} \mathrm{AlB}_{2}$ and $\mathrm{Mo}_{4 / 3} \mathrm{Sc}_{2 / 3} \mathrm{AlB}_{2}$ including atomic coordinates; DFToptimized crystallographic data and dynamical stability for all $\mathrm{Mo}_{4 / 3} \mathrm{Y}_{2 / 3} \mathrm{AlB}_{2}$ and $\mathrm{Mo}_{4 / 3} \mathrm{Sc}_{2 / 3} \mathrm{AlB}$ candidate structures; equilibrium simplex, powder $\mathrm{X}$-ray diffraction data for samples containing $\mathrm{Mo}_{4 / 3} \mathrm{Sc}_{2 / 3} \mathrm{AlB}_{2}$; simulated powder X-ray diffractograms for all $\mathrm{Mo}_{4 / 3} \mathrm{Y}_{2 / 3} \mathrm{AlB}_{2}$ and $\mathrm{Mo}_{4 / 3} \mathrm{Sc}_{2 / 3} \mathrm{AlB}$ candidate structures; additional electron microscopy images; additional simulated selected-area electron diffraction patterns; and EDX data (PDF)

\section{AUTHOR INFORMATION}

\section{Corresponding Authors}

Martin Dahlqvist - Thin Film Physics, Department of Physics, Chemistry and Biology (IFM), Linköping University, SE-581 83 Linköping, Sweden; 다 orcid.org/0000-0001-5036-2833; Email: martin.dahlqvist@liu.se

Johanna Rosen - Thin Film Physics, Department of Physics, Chemistry and Biology (IFM), Linköping University, SE-581 83 Linköping, Sweden; 다이.org/0000-0002-5173-6726; Email: johanna.rosen@liu.se

\section{Authors}

Quanzheng Tao - Thin Film Physics, Department of Physics, Chemistry and Biology (IFM), Linköping University, SE-581 83 Linköping, Sweden; (ㅇ orcid.org/0000-0002-4073-5242

Jie Zhou - Thin Film Physics, Department of Physics, Chemistry and Biology (IFM), Linköping University, SE-581 83 Linköping, Sweden

Justinas Palisaitis - Thin Film Physics, Department of Physics, Chemistry and Biology (IFM), Linköping University, SE-581 83 Linköping, Sweden

Per O. Å. Persson - Thin Film Physics, Department of Physics, Chemistry and Biology (IFM), Linköping University, SE-581 83 Linköping, Sweden; (1) orcid.org/0000-0001-9140-6724

Complete contact information is available at:

https://pubs.acs.org/10.1021/jacs.0c08113

\section{Notes}

The authors declare no competing financial interest. 


\section{ACKNOWLEDGMENTS}

J.R. acknowledges support from the Knut and Alice Wallenberg (KAW) Foundation for a fellowship/scholar grant and project funding (KAW 2015.0043) and from the Swedish Foundation for Strategic Research (SSF) for project funding (EM16-0004). The Knut and Alice Wallenberg (KAW) Foundation is also acknowledged for support of the Linköping Electron Microscopy Laboratory. The Swedish Research council is gratefully acknowledged through projects 2019-05047, 201904233, and 2016-04412. P.O.A..P. acknowledges the Swedish Foundation for Strategic Research (SSF) through the Research Infrastructure Fellow Program (no. RIF 14-0074). Support from the Swedish Government Strategic Research Area in Materials Science on Functional Materials at Linköping University (Faculty Grant SFO-Mat-LiU No 2009 00971) is also acknowledged. The calculations were carried out using supercomputer resources provided by the Swedish National Infrastructure for Computing (SNIC) at the National Supercomputer Centre (NSC), the High Performance Computing Center North (HPC2N), and the PDC Center for High Performance Computing.

\section{ABBREVIATIONS}

$i$-MAB in-plane-ordered quaternary MAB phase $i$-MAX in-plane-ordered quaternary MAX phase SQS special quasi-random structure.

\section{REFERENCES}

(1) Barsoum, M. W. The $M_{N+1} A_{N}$ phases: A new class of solids; Thermodynamically stable nanolaminates. Prog. Solid State Chem. 2000, 28 (1-4), 201-281.

(2) Barsoum, M. W. MAX Phases, Properties of Machinable Ternary Carbides and Nitrides; Wiley: New York, 2013.

(3) Naguib, M.; Kurtoglu, M.; Presser, V.; Lu, J.; Niu, J.; Heon, M.; Hultman, L.; Gogotsi, Y.; Barsoum, M. W. Two-dimensional nanocrystals produced by exfoliation of $\mathrm{Ti}_{3} \mathrm{AlC}_{2}$. Adv. Mater. 2011, 23 (37), 4248-4253.

(4) Anasori, B.; Lukatskaya, M. R.; Gogotsi, Y. 2D metal carbides and nitrides (MXenes) for energy storage. Nat. Rev. Mater. 2017, 2, 16098.

(5) Shahzad, F.; Alhabeb, M.; Hatter, C. B.; Anasori, B.; Man Hong, S.; Koo, C. M.; Gogotsi, Y. Electromagnetic interference shielding with 2D transition metal carbides (MXenes). Science 2016, 353 (6304), 1137-1140.

(6) Tao, Q.; Dahlqvist, M.; Lu, J.; Kota, S.; Meshkian, R.; Halim, J.; Palisaitis, J.; Hultman, L.; Barsoum, M. W.; Persson, P. O. Å.; Rosen, J. Two-dimensional $\mathrm{Mo}_{1.33} \mathrm{C}$ MXene with divacancy ordering prepared from parent $3 \mathrm{D}$ laminate with in-plane chemical ordering. Nat. Commun. 2017, 8, 14949.

(7) Dahlqvist, M.; Lu, J.; Meshkian, R.; Tao, Q.; Hultman, L.; Rosen, $\mathrm{J}$. Prediction and synthesis of a family of atomic laminate phases with Kagomé-like and in-plane chemical ordering. Sci. $A d v .2017,3$ (7), No. e1700642.

(8) Meshkian, R.; Dahlqvist, M.; Lu, J.; Wickman, B.; Halim, J.; Thörnberg, J.; Tao, Q.; Li, S.; Intikhab, S.; Snyder, J.; Barsoum, M. W.; Yildizhan, M.; Palisaitis, J.; Hultman, L.; Persson, P. O. Å.; Rosen, $\mathrm{J}$. W-based atomic laminates and their $2 \mathrm{D}$ derivative $\mathrm{W}_{1.33} \mathrm{C}$ MXene with vacancy ordering. Adv. Mater. 2018, 30, 1706409.

(9) Persson, I.; Ghazaly, A. e.; Tao, Q.; Halim, J.; Kota, S.; Darakchieva, V.; Palisaitis, J.; Barsoum, M. W.; Rosen, J.; Persson, P. O. Å. Tailoring Structure, Composition, and Energy Storage Properties of MXenes from Selective Etching of In-Plane, Chemically Ordered MAX Phases. Small 2018, 14, 1703676.

(10) Becher, H. J.; Krogmann, K.; Peisker, E. Über das ternäre Borid $\mathrm{Mn}_{2} \mathrm{AlB}_{2}$. Z. Anorg. Allg. Chem. 1966, 344 (3-4), 140-147.
(11) Wang, J.; Ye, T.-N.; Gong, Y.; Wu, J.; Miao, N.; Tada, T.; Hosono, H. Discovery of hexagonal ternary phase $\mathrm{Ti}_{2} \mathrm{InB}_{2}$ and its evolution to layered boride TiB. Nat. Commun. 2019, 10 (1), 2284.

(12) Ade, M.; Hillebrecht, H. Ternary Borides $\mathrm{Cr}_{2} \mathrm{AlB}_{2}, \mathrm{Cr}_{3} \mathrm{AlB}_{4}$, and $\mathrm{Cr}_{4} \mathrm{AlB}_{6}$ : The First Members of the Series $\left(\mathrm{CrB}_{2}\right)_{n} \mathrm{CrAl}$ with $n=$ 1, 2, 3 and a Unifying Concept for Ternary Borides as MAB-Phases. Inorg. Chem. 2015, 54 (13), 6122-6135.

(13) Zhang, H.; Dai, F.-Z.; Xiang, H.; Zhang, Z.; Zhou, Y. Crystal structure of $\mathrm{Cr}_{4} \mathrm{AlB}_{4}$ : a new $\mathrm{MAB}$ phase compound discovered in $\mathrm{Cr}$ Al-B system. J. Mater. Sci. Technol. 2019, 35 (4), 530-534.

(14) Tan, X.; Chai, P.; Thompson, C. M.; Shatruk, M. Magnetocaloric Effect in $\mathrm{AlFe}_{2} \mathrm{~B}_{2}$ : Toward Magnetic Refrigerants from EarthAbundant Elements. J. Am. Chem. Soc. 2013, 135 (25), 9553-9557.

(15) Chai, P.; Stoian, S. A.; Tan, X.; Dube, P. A.; Shatruk, M. Investigation of magnetic properties and electronic structure of layered-structure borides $\mathrm{AlT}_{2} \mathrm{~B}_{2}(\mathrm{~T}=\mathrm{Fe}, \mathrm{Mn}, \mathrm{Cr})$ and $\mathrm{AlFe}_{2-\mathrm{x}} \mathrm{Mn}_{\mathrm{x}} \mathrm{B}_{2}$. J. Solid State Chem. 2015, 224, 52-61.

(16) Okada, S.; Iizumi, K.; Kudaka, K.; Kudou, K.; Miyamoto, M.; Yu, Y.; Lundström, T. Single Crystal Growth of $\left(\mathrm{Mo}_{\mathrm{X}} \mathrm{Cr}_{1-\mathrm{X}}\right) \mathrm{AlB}$ and $\left(\mathrm{Mo}_{\mathrm{X}} \mathrm{W}_{1-\mathrm{X}}\right) \mathrm{AlB}$ by Metal Al Solutions and Properties of the Crystals. J. Solid State Chem. 1997, 133 (1), 36-43.

(17) Ke, L.; Harmon, B. N.; Kramer, M. J. Electronic structure and magnetic properties in $\mathrm{T}_{2} \mathrm{AlB}_{2}(\mathrm{~T}=\mathrm{Fe}, \mathrm{Mn}, \mathrm{Cr}, \mathrm{Co}$, and $\mathrm{Ni})$ and their alloys. Phys. Rev. B: Condens. Matter Mater. Phys. 2017, 95 (10), 104427.

(18) Dai, F.-Z.; Xiang, H.; Sun, Y.; Zhou, Y. $\mathrm{M}_{2} \mathrm{M}^{\prime} \mathrm{AlB}_{4}(\mathrm{M}=\mathrm{Mn}$, $\left.\mathrm{Fe}, \mathrm{Co}, \mathrm{M}^{\prime}=\mathrm{Cr}, \mathrm{Mo}, \mathrm{W}\right)$ : Theoretical predicted ordered MAB phases with $\mathrm{Cr}_{3} \mathrm{AlB}_{4}$ crystal structure. J. Mater. Sci. Technol. 2019, 35 (7), 1432-1438.

(19) Blöchl, P. E. Projector augmented-wave method. Phys. Rev. B: Condens. Matter Mater. Phys. 1994, 50 (24), 17953-17979.

(20) Kresse, G.; Joubert, D. From ultrasoft pseudopotentials to the projector augmented-wave method. Phys. Rev. B: Condens. Matter Mater. Phys. 1999, 59 (3), 1758-1775.

(21) Kresse, G.; Hafner, J. Ab initio molecular dynamics for liquid metals. Phys. Rev. B: Condens. Matter Mater. Phys. 1993, 47 (1), 558561.

(22) Kresse, G.; Furthmüller, J. Efficiency of ab-initio total energy calculations for metals and semiconductors using a plane-wave basis set. Comput. Mater. Sci. 1996, 6 (1), 15-50.

(23) Kresse, G.; Furthmüller, J. Efficient iterative schemes for $a b$ initio total-energy calculations using a plane-wave basis set. Phys. Rev. B: Condens. Matter Mater. Phys. 1996, 54 (16), 11169-11186.

(24) Perdew, J. P.; Burke, K.; Ernzerhof, M. Generalized gradient approximation made simple. Phys. Rev. Lett. 1996, 77 (18), 38653868.

(25) Monkhorst, H. J.; Pack, J. D. Special points for Brillouin-zone integrations. Phys. Rev. B 1976, 13 (12), 5188-5192.

(26) Momma, K.; Izumi, F. VESTA 3 for three-dimensional visualization of crystal, volumetric and morphology data. J. Appl. Crystallogr. 2011, 44 (6), 1272-1276.

(27) van de Walle, A.; Ceder, G. Automating first-principles phase diagram calculations. J. Phase Equilib. 2002, 23 (4), 348.

(28) van de Walle, A.; Asta, M.; Ceder, G. The alloy theoretic automated toolkit: A user guide. CALPHAD: Comput. Coupling Phase Diagrams Thermochem. 2002, 26 (4), 539-553.

(29) Zunger, A.; Wei, S. H.; Ferreira, L. G.; Bernard, J. E. Special quasirandom structures. Phys. Rev. Lett. 1990, 65 (3), 353-356.

(30) Dahlqvist, M.; Alling, B.; Abrikosov, I. A.; Rosén, J. Phase stability of $\mathrm{Ti}_{2} \mathrm{AlC}$ upon oxygen incorporation: A first-principles investigation. Phys. Rev. B: Condens. Matter Mater. Phys. 2010, 81 (2), 024111.

(31) Dahlqvist, M.; Alling, B.; Rosén, J. Stability trends of MAX phases from first principles. Phys. Rev. B: Condens. Matter Mater. Phys. 2010, 81 (22), 220102.

(32) Eklund, P.; Dahlqvist, M.; Tengstrand, O.; Hultman, L.; Lu, J.; Nedfors, N.; Jansson, U.; Rosén, J. Discovery of the ternary nanolaminated compound $\mathrm{Nb}_{2} \mathrm{GeC}$ by a systematic theoreticalexperimental approach. Phys. Rev. Lett. 2012, 109 (3), 035502. 
(33) Ingason, A. S.; Mockute, A.; Dahlqvist, M.; Magnus, F.; Olafsson, S.; Arnalds, U. B.; Alling, B.; Abrikosov, I. A.; Hjörvarsson, B.; Persson, P. O. Å.; Rosen, J. Magnetic self-organized atomic laminate from first principles and thin film synthesis. Phys. Rev. Lett. 2013, 110 (19), 195502.

(34) Ingason, A. S.; Petruhins, A.; Dahlqvist, M.; Magnus, F.; Mockute, A.; Alling, B.; Hultman, L.; Abrikosov, I. A.; Persson, P. O. Å.; Rosen, J. A nanolaminated magnetic phase: $\mathrm{Mn}_{2} \mathrm{GaC}$. Mater. Res. Lett. 2014, 2 (2), 89-93.

(35) Mockute, A.; Dahlqvist, M.; Emmerlich, J.; Hultman, L.; Schneider, J. M.; Persson, P. O. Å.; Rosen, J. Synthesis and ab initio calculations of nanolaminated $(\mathrm{Cr}, \mathrm{Mn})_{2} \mathrm{AlC}$ compounds. Phys. Rev. B: Condens. Matter Mater. Phys. 2013, 87 (9), 094113.

(36) Mockute, A.; Persson, P. O. Å.; Magnus, F.; Ingason, A. S.; Olafsson, S.; Hultman, L.; Rosen, J. Synthesis and characterization of arc deposited magnetic $(\mathrm{Cr}, \mathrm{Mn})_{2} \mathrm{AlC}$ MAX phase films. Phys. Status Solidi RRL 2014, 8 (5), 420-423.

(37) Rietveld, H. A profile refinement method for nuclear and magnetic structures. J. Appl. Crystallogr. 1969, 2, 65-71.

(38) Rodríguez-Carvajal, J. Recent advances in magnetic structure determination by neutron powder diffraction. Phys. B 1993, 192 (1), 55-69.

(39) Chaban, N. F.; Kuz'Ma, I. U. B. Ternary systems Cr-Al-B and Mn-Al-B. Neorg. Mater. 1973, 9, 1908-1911.

(40) Jeitschko, W. The crystal structure of $\mathrm{Fe}_{2} \mathrm{AlB}_{2}$. Acta Crystallogr., Sect. B: Struct. Crystallogr. Cryst. Chem. 1969, B25, 163.

(41) Dahlqvist, M.; Petruhins, A.; Lu, J.; Hultman, L.; Rosen, J. Origin of Chemically Ordered Atomic Laminates (i-MAX): Expanding the Elemental Space by a Theoretical/Experimental Approach. ACS Nano 2018, 12 (8), 7761-7770.

(42) Rackl, T.; Eisenburger, L.; Niklaus, R.; Johrendt, D. Syntheses and physical properties of the MAX phase boride $\mathrm{Nb}_{2} \mathrm{SB}$ and the solid solutions $\mathrm{Nb}_{2} \mathrm{SBxC}_{1-x}(x=0-1)$. Phys. Rev. Mater. 2019, 3 (5), 054001 .

(43) Rackl, T.; Johrendt, D. The MAX phase borides $\mathrm{Zr}_{2} \mathrm{SB}$ and $\mathrm{Hf}^{2} \mathrm{SB}$. Solid State Sci. 2020, 106, 106316.

(44) Lu, J.; Thore, A.; Meshkian, R.; Tao, Q.; Hultman, L.; Rosen, J. Theoretical and experimental exploration of a novel in-plane chemically-ordered $\left(\mathrm{Cr}_{2 / 3} M_{1 / 3}\right)_{2} \mathrm{AlC}$ i-MAX phase with $\mathrm{M}=\mathrm{Sc}$ and Y. Cryst. Cryst. Growth Des. 2017, 17 (11), 5704-5711.

(45) Chen, L.; Dahlqvist, M.; Lapauw, T.; Tunca, B.; Wang, F.; Lu, J.; Meshkian, R.; Lambrinou, K.; Blanpain, B.; Vleugels, J.; Rosen, J. Theoretical Prediction and Synthesis of $\left(\mathrm{Cr}_{2 / 3} \mathrm{Zr}_{1 / 3}\right)_{2} \mathrm{AlC}$ i-MAX Phase. Inorg. Chem. 2018, 57 (11), 6237-6244.

(46) Halim, J.; Palisaitis, J.; Lu, J.; Thörnberg, J.; Moon, E. J.; Precner, M.; Eklund, P.; Persson, P. O. Å.; Barsoum, M. W.; Rosen, J. Synthesis of Two-Dimensional $\mathrm{Nb}_{1.33} \mathrm{C}$ (MXene) with Randomly Distributed Vacancies by Etching of the Quaternary Solid Solution $\left(\mathrm{Nb}_{2 / 3} \mathrm{Sc}_{1 / 3}\right)_{2} \mathrm{AlC}$ MAX Phase. ACS Applied Nano Materials 2018, 1 (6), 2455-2460.

(47) Champagne, A.; Chaix-Pluchery, O.; Ouisse, T.; Pinek, D.; Gélard, I.; Jouffret, L.; Barbier, M.; Wilhelm, F.; Tao, Q.; Lu, J.; Rosen, J.; Barsoum, M. W.; Charlier, J. C. First-order Raman scattering of rare-earth containing $i$-MAX single crystals $\left(\mathrm{Mo}_{2 / 3} \mathrm{RE}_{1 / 3}\right)_{2} \mathrm{AlC}(\mathrm{RE}=\mathrm{Nd}, \mathrm{Gd}, \mathrm{Dy}, \mathrm{Ho}, \mathrm{Er})$. Phys. Rev. Mater. 2019, 3 (5), 053609.

(48) Petruhins, A.; Dahlqvist, M.; Lu, J.; Hultman, L.; Rosen, J. Theoretical prediction and experimental verification of the chemically-ordered atomic-laminate $i$-MAX phases $\left(\mathrm{Cr}_{2 / 3} \mathrm{Sc}_{1 / 3}\right)_{2} \mathrm{GaC}$ and $\left(\mathrm{Mn}_{2 / 3} \mathrm{Sc}_{1 / 3}\right)_{2}$ GaC. Cryst. Cryst. Growth Des. 2020, 20 (1), 55-61.

(49) Petruhins, A.; Lu, J.; Hultman, L.; Rosen, J. Synthesis of atomically layered and chemically ordered rare-earth (RE) $i$-MAX phases; $\left(\mathrm{Mo}_{2 / 3} \mathrm{RE}_{1 / 3}\right)_{2} \mathrm{GaC}$ with $\mathrm{RE}=\mathrm{Gd}, \mathrm{Tb}, \mathrm{Dy}, \mathrm{Ho}, \mathrm{Er}, \mathrm{Tm}, \mathrm{Yb}$, and Lu. Mater. Res. Lett. 2019, 7 (11), 446-452.

(50) Tao, Q.; Lu, J.; Dahlqvist, M.; Mockute, A.; Calder, S.; Petruhins, A.; Meshkian, R.; Rivin, O.; Potashnikov, D.; Caspi, E. a.; Shaked, H.; Hoser, A.; Opagiste, C.; Galera, R.-M.; Salikhov, R.; Wiedwald, U.; Ritter, C.; Wildes, A. R.; Johansson, B.; Hultman, L.; Farle, M.; Barsoum, M. W.; Rosen, J. Atomically Layered and Ordered
Rare-Earth i-MAX Phases: A New Class of Magnetic Quaternary Compounds. Chem. Mater. 2019, 31 (7), 2476-2485.

(51) Thörnberg, J.; Halim, J.; Lu, J.; Meshkian, R.; Palisaitis, J.; Hultman, L.; Persson, P. O. Å.; Rosen, J. Synthesis of $\left(\mathrm{V}_{2 / 3} \mathrm{Sc}_{1 / 3}\right)_{2} \mathrm{AlC}$ $i$-MAX phase and $\mathrm{V}_{2-\mathrm{x}} \mathrm{C}$ MXene scrolls. Nanoscale 2019, 11 (31), 14720-14726.

(52) Mockute, A.; Tao, Q.; Dahlqvist, M.; Lu, J.; Calder, S.; Caspi, E. N.; Hultman, L.; Rosen, J. Materials synthesis, neutron powder diffraction, and first-principles calculations of $\left(\mathrm{Mo}_{x} \mathrm{Sc}_{1-x}\right)_{2} \mathrm{AlC} i$-MAX phase used as parent material for MXene derivation. Phys. Rev. Mater. 2019, 3 (11), 113607.

(53) Srimuk, P.; Halim, J.; Lee, J.; Tao, Q.; Rosen, J.; Presser, V. Two-Dimensional Molybdenum Carbide (MXene) with Divacancy Ordering for Brackish and Seawater Desalination via Cation and Anion Intercalation. ACS Sustainable Chem. Eng. 2018, 6 (3), 37393747.

(54) Qin, L.; Tao, Q.; El Ghazaly, A.; Fernandez-Rodriguez, J.; Persson, P. O. Å.; Rosen, J.; Zhang, F. High-Performance Ultrathin Flexible Solid-State Supercapacitors Based on Solution Processable $\mathrm{Mo}_{1.33} \mathrm{C}$ MXene and PEDOT:PSS. Adv. Funct. Mater. 2018, 28 (2), 1703808.

(55) Lind, H.; Halim, J.; Simak, S. I.; Rosen, J. Investigation of vacancy-ordered $\mathrm{Mo}_{1.33} \mathrm{C}$ MXene from first principles and $\mathrm{x}$-ray photoelectron spectroscopy. Phys. Rev. Mater. 2017, 1 (4), 044002.

(56) Ahmed, B.; Ghazaly, A. E.; Rosen, J. i-MXenes for Energy Storage and Catalysis. Adv. Funct. Mater. 2020, 2000894.

(57) Meshkian, R.; Lind, H.; Halim, J.; El Ghazaly, A.; Thörnberg, J.; Tao, Q.; Dahlqvist, M.; Palisaitis, J.; Persson, P. O. Å.; Rosen, J. Theoretical Analysis, Synthesis, and Characterization of $2 \mathrm{D} \mathrm{W}_{1.33} \mathrm{C}$ (MXene) with Ordered Vacancies. ACS Applied Nano Materials 2019, 2 (10), 6209-6219. 